\title{
Low Frequency Pulsed Current and Pressure Ulcer Healing
}

\author{
Aleksandra Jerčinović, Renata Karba, Student Member, IEEE, Lojze Vodovnik, Fellow, IEEE, \\ Aneta Stefanovska, Member, IEEE, Peter Krošelj, Rajko Turk, Ivan Džidić, Helena Benko, and Rajmond Šavrin
}

\begin{abstract}
In spite of the extensive clinical work reported in the area of electrical wound healing, electrical stimulation to augment chronic wound repair is still far from being widely accepted in clinical practice. Problems in designing clinical studies (size of the sample observed, control group, ethics of the procedure), evaluating treatment efficacy, rationales for use of the treatment, and unknown underlying mechanisms contribute to the aforementioned fact. In the present study, we evaluated low frequency electrical current for its beneficial effects in pressure ulcer management. Seventy-three spinal cord injured patients with 109 pressure ulcers participated in the study. Patients were randomly assigned to a control group receiving conventional treatment of their ulcers, or to a stimulation group, in which the ulcers were additionally treated with low frequency pulsed current. A comparison of the two groups showed significantly higher average healing rate for the stimulated group. Patients from the control group had the opportunity of crossing over to the stimulation group after the required control period of four weeks. This group (the crossover group) was analyzed separately. In all but one ulcer out of 20 , an improvement in the healing process was observed after electrical stimulation was initiated.
\end{abstract}

Index Terms-Electric stimulation, electrotherapy, wound healing, pressure ulcer.

\section{INTRODUCTION}

$\mathbf{F}$ IOR SPINAL cord injured (SCI) patients, pressure ulcers are a troublesome problem in rehabilitation. Patients are subject to the discomfort, stress, and high costs of longterm conventional treatment required for the healing of such ulcerations [1], [2]. The development of a pressure ulcer involves intrinsic and extrinsic factors [3]. Important intrinsic contributors to the development of pressure ulcers in SCI patients are sensory loss and loss of vasomotor control resulting in the lowering of tissue resistance to pressure, especially in the early stages following the spinal cord lesion [3], [4]. The most decisive extrinsic factor contributing to the formation of these typical chronic wounds is repetitive and prolonged pressure on particular parts of the body (most commonly over bony prominences: sacrum, trochanters, heels,

Manuscript received October 26, 1992; revised August 26, 1994. This work was supported by the Ministry of Science and Technology of the Republic of Slovenia, and the National Institute for Disability and Rehabilitation Research, Department of Education, Washington D.C., USA.

A. Jerčinović, R. Karba, L. Vodovnik, A. Stefanovska, and P. Krošelj are with the Laboratory of Biocybernetics, Faculty of Electrical and Computer Engineering, University of Ljubljana, 61000 Ljubljana, Slovenia.

R. Turk, H. Benko, and R. Šavrin are with the University Rehabilitation Institute, University of Ljubljana, 61000 Ljubljana, Slovenia.

I. Džidić is with the Health Resort Varaždinske Toplice, Croatia.

IEEE Log Number 9406446. etc.). The combination of these intrinsic and extrinsic factors causes a complex chain of processes resulting in pressureinduced ischemia, which is considered to be the primary cause of pressure ulcer formation [4]. Even the most attentive conventional medical care, the use of a special pressure relieving device, and a carefully chosen diet often prove ineffective in prevention of pressure ulcer formation and/or initiation of the healing process. Very often, pressure ulcers prove to be resistant to standard therapy for several months or even years, developing into a chronic state and requiring plastic surgery. These wounds are also common among other immobile patients and the elderly [5]. A variety of nonstandard treatments for chronic wounds, such as electrical [6]-[17] and electromagnetic [18], [19] stimulation, hyperbaric oxygen treatment [20], use of ultrasound [21], and recently, the use of growth factors [22], [23] have been recommended. In spite of the favorable results reported, these methods are frequently considered curiosities, not potential remedies. Some arguments against wider application of the aforementioned treatments have arisen from critics of the studies and merit careful consideration. The major objections relate to:

- lack of controlled studies,

- inadequate quantification of the healing process, and

- ignorance regarding the mechanisms through which treatment might influence healing.

A survey of the existing literature on chronic woundmanagement reveals that, since the 1960's, numerous clinical studies have been performed on the application of various types of electrical and electromagnetic stimulation [24]. Besides the aforementioned objections, scepticism and confusion has been further increased by the variety of electrical stimulation patterns proposed for chronic wound management. In five of the studies, constant direct current (DC) stimulation was used [6]-[10]. A controlled study using DC stimulation was performed by Carley and Wainapel, and their results showed a 1.5 to 2.5 times faster healing rate for the treated group as compared to the control group [10]. Pulsed low intensity direct current $(300-600 \mu \mathrm{A})$ has been shown to accelerate healing of indolent pressure ulcers in the study by Wood et al. [11]. Pulsed direct current of somewhat higher amplitude (29.2 $\mathrm{mA}$ ) has been employed for the treatment of chronic dermal ulcers (pressure ulcers, ulcers caused by vascular insufficiency, trauma or surgery) by Feedar et al. [12]. The polarity of the stimulation electrode on the wound, as well as the pulse frequency, have been changed during the course of the study. This led to quite a complicated stimulation protocol for which 
no convincing explanation is given. However, a significant beneficial effect on healing of treated chronic dermal ulcers was observed. Two studies dealing with a homogeneous population of patients with pressure ulcers demonstrated accelerated healing due to stimulation with high voltage pulsed direct current (twin-peaked pulses of 100-200 V, 100 pps) [13], [14]. The polarity of the treatment electrode on the wound was kept negative in the study by Griffin et al. [13], while it was alternated in the study by Kloth and Feedar [14]. Biphasic pulsed current (pulse duration of $0.4 \mathrm{~ms}$, frequency of $80 \mathrm{pps}$ ) has been employed for preventing and reversing established ischemia in skin flaps of patients who underwent reconstructive surgery for mammary carcinoma [15]. The same type of biphasic pulsed electrical stimulation as used in the present study has been shown to have a beneficial effect on healing of vascular wounds, pressure ulcers in geriatric patients, and posttraumatic wounds [16]. Kaada reported that low frequency transcutaneous electrical stimulation applied at remote sites (acupuncture points on the hand) promoted healing of chronic ischemic ulcerations [17]. In a double blind study on the effects of low-frequency pulsed electromagnetic fields on skin ulcers of venous origin, an improvement in the healing process of stimulated ulcers was reported by Ieran et al. [19].

Our rationale for using electrical stimulation (ES) to enhance wound healing was based on observations of some positive side effects of functional electrical stimulation (FES) which is being routinely used in paretic and paralyzed patients. Besides eliciting functional movement, the therapeutic effects of ES were also noted [25], [26]. The aforementioned patient population is at high risk of developing pressure ulcers. However, patients included in the FES rehabilitation program developed markedly fewer pressure ulcers, and surprisingly, existing chronic ulcers healed at a faster rate.

In order to verify this observation, we used the same ES parameters as in our FES program, except current amplitudes, and performed a study on the effects of electrotherapy on chronic wound healing. In this paper, the quantitative data obtained from a six-year controlled study will be presented. Pressure ulcer etiology is not yet totally understood and the healing mechanisms involve complex processes in a nonhomogeneous population. In view of the numerous stratification variables to be considered - such as age, duration of disability, ulcer area, depth, location, duration of ulcer prior to inclusion in the study, etc.-it is difficult to conduct an adequately controlled study. This is why a protocol comprising random parallel group-study and crossover study elements was carried out.

We present a comparison of the results obtained from the control and ES groups, both of which were treated with conventional wound care methods, but in addition, ulcers in the stimulated group also received pulsed current electrical stimulation. This paper emphasizes the data obtained from the group which crossed over from the control group to the stimulated group. A characteristic of the crossover group is that each ulcer served as its own control, thus assuring that most of the aforementioned variables were constant. The possible physiological mechanisms through which ES might have affected wound healing are discussed.

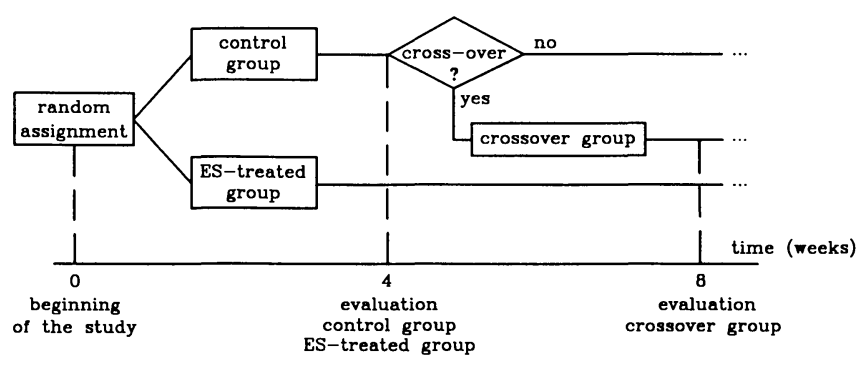

Fig. 1. Study design.

\section{EXPERIMENTAL METHOD}

\section{A. Subjects}

Seventy-three subjects with 109 pressure ulcers altogether participated in this study. The patients ranged in age from 18 to 68 years ( $36 \pm 15$ years, mean \pm standard deviation). All subjects were volunteers from the spinal cord injured inpatient population. They had no known additional diagnosis for diabetes, vascular disease, or cancer. When included in the study, the patients had been disabled from one month to several years ( $32 \pm 60$ months, mean \pm standard deviation). The pressure ulcers had developed in the decentralized skin below the spinal cord lesion level and, prior to patients entering the study, they were treated only with standard wound care. Twenty-four patients had more than one pressure ulcer at a time. The duration of the pressure ulcers before they were included in this study varied from one month to several years. Out of 109 ulcers, 34 were located on the sacral area, 28 on critical areas of the legs (heel, foot, knee), 27 on the trochanter areas, 9 on the gluteal area, and 11 on other locations.

\section{B. Study Design}

The patients were examined by a physician for an initial assessment of their wound status and related factors. The experimental procedure was explained to them and all patients agreed to participate in the study by signing an informed consent form. The format of our study design is shown in Fig. 1. Patients were randomly assigned either to a control group, where they received standard wound care treatment, or to a stimulation group (ES-treated group) in which ulcers were additionally treated with ES. After four weeks, i.e., at the end of the required control period, patients from the control group were offered the opportunity of crossing over to the ES-treated group. This was also done for obvious ethical reasons.

\section{Control Group}

The 31 patients assigned to the control group received standard treatment of their ulcers [27]. The standard treatment included initial selective debridement, the application of a new standard dressing to the ulcer two or more times per day, as needed, and a broad spectrum antibiotic in cases of infection, which were rather rare. The SCI patients included in the study were lying on dry-floatation mattresses and were turned to a new position every four hours during the night. The patients were included in the standard rehabilitation program 


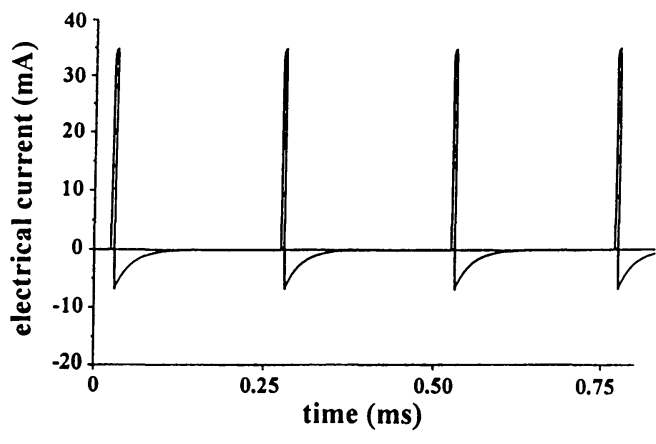

(a)

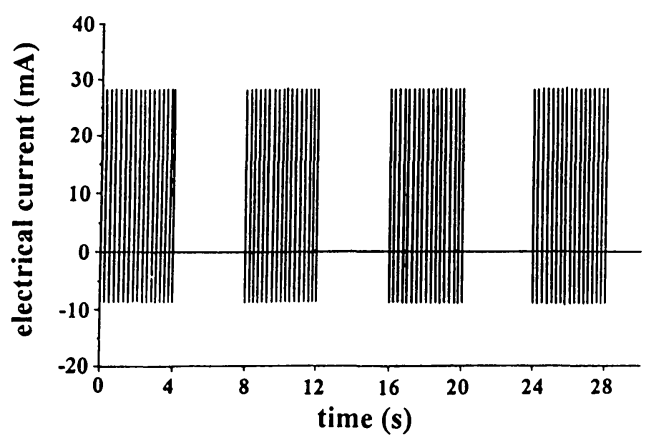

(b)

Fig. 2. (a) Biphasic, asymmetric pulsed current stimuli. (b) Electrical stimulation duty cycle (redrawn from [16]).

(FES excluded), one to two hours per day, depending on their conditions.

\section{ES-Treated Group}

In addition to the conventional treatment, the 42 patients in this group received two hours of ES daily, five days a week. The ES was delivered through the ulcer tissues via two flexible self-adhering electrodes measuring 75 or $50 \mathrm{~mm}$ in diameter (Pals plus, Axelgaard Manufacturing) which were placed on healthy skin approximately $3 \mathrm{~cm}$ from the edge of the ulcer. Biphasic, asymmetric, charge-balanced pulses having a repetition frequency of $40 \mathrm{pps}$ and a pulse duration of $250 \mu$ s were used. Pulses were delivered repeatedly in trains lasting $4 \mathrm{~s}$, followed by a 4 -s pause (Fig. 2). The amplitude was adjusted (up to $35 \mathrm{~mA}$ ) for each patient individually to achieve minimal muscle contraction, when feasible. Because of visible muscle contractions, it was not possible to conduct a double-blind clinical trial.

\section{E. Crossover Group}

This group included patients who, after four weeks of conventional treatment, experienced ES treatment, as described above.

\section{F. Evaluation of the Healing Process}

To evaluate the healing process, weekly measurements of the wound area were performed. Changes in other very important ulcer measurements, such as the wound depth and the appearance of granulation, were recorded as well. Data

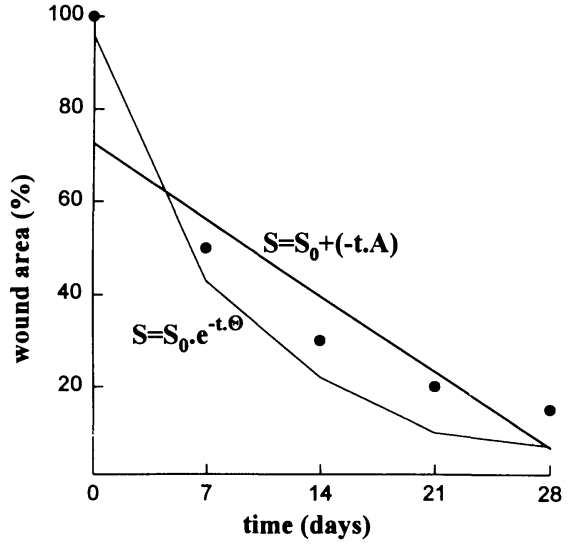

Fig. 3. Illustration of the linear and exponential fitting method and corresponding healing rates.

obtained during the first four weeks of treatment were included in the data analysis for evaluation of treatment outcomes.

An attempt to describe and assess the healing process or the rate of healing raised the question regarding the criteria which optimally govern the time-courses of the measured wound areas. Most researchers assume the healing process is linear. Others claim that for the majority of chronic wounds the fitting errors are reduced when exponential fitting is applied, i.e., the healing process exhibits an exponential behavior [3], [28], [29]. In order to avoid any of the mentioned assumptions, we will evaluate obtained wound area values using both quantification methods (Fig. 3), which could be described by the following equations:

exponential fitting

linear fitting

$$
\begin{aligned}
S_{\exp } & =S_{0} * e^{-t \Theta}, \\
S_{\text {lin }} & =S_{0}+(-A * t),
\end{aligned}
$$

where $S_{0}$ represents the fitted initial wound area, $S_{\exp }$ and $S_{\text {lin }}$ are the wound area at time $t$, and $\Theta$ and $A$ are the healing rates for the best exponential and linear fitting, respectively. The parameters $\Theta$ and $A$, as a measure of the rate of wound healing expressed in \% per day, are illustrated in the following manner: if healing rate $=0$, the wound area remains unchanged, if healing rate $<0$, the wound area is increasing, and if healing rate $>0$, the wound area is decreasing. The capability of each model (exponential and linear) to describe the healing process can be evaluated by fitting errors. They are defined as

$$
\begin{aligned}
& \text { exp. fitting error } \quad \varepsilon_{\exp }=\frac{\sum_{i=0 . .4}\left(S_{m i}-S_{\exp i}\right)^{2}}{\sum_{i=0 . .4} S_{m i}^{2}} * 100(\%) \\
& \text { linear fitting error } \quad \varepsilon_{\operatorname{lin}}=\frac{\sum_{i=0 . .4}\left(S_{m i}-S_{\operatorname{lin} i}\right)^{2}}{\sum_{i=0 . .4} S_{m i}^{2}} * 100(\%)
\end{aligned}
$$

where $S_{m i}$ represents the measured value of the ulcer area after the $i$-th week of treatment, $S_{\exp i}$ is the exponentially fitted ulcer area for the $i$-th week, and $S_{\text {lini }}$ is the linearly fitted ulcer area for the $i$-th week.

The main purpose of our study was to test for the beneficial effects of pulsed ES treatment. In accordance with the study design involving two parallel groups and the crossover group, the statistical tests were as follows:

1) for the parallel groups (control and ES-treated group), the hypothesis that ulcers in the control group heal at 
the same rate as those treated with low frequency pulsed current was tested using the two-sample $t$-test (separate variance estimate),

2) for the crossover group, the healing rate was statistically established by comparing the healing rate for the control period with that of the ES-treatment period, by means of the paired $t$-test, and

3 ) the equality of the exponential and linear fitting error was tested using the paired $t$-test. For each test, the difference was regarded as statistically significant if the probability of an error of the first kind was less than 0.05 .

\section{RESULTS}

\section{A. Control Versus ES-Treated Group}

Table I summarizes the data concerning ulcers included in the study. An imbalance in the average initial values of ulcer size and duration between the control and EStreated group was introduced by random assignment of patients to these groups. Ulcers in the control group were more complex regarding their initial size, and those in the EStreated group regarding their tissue characteristics (appearance of granulation or necrotic tissue) and their duration prior to inclusion in the study. In comparing healing rates, the results (Fig. 4) show that the mean healing rate for the ES-treated group during the first four weeks was $2.2 \%$ for linear and $5.7 \%$ per day for the exponential fitting method, which is higher than the mean healing rate for the control group during the same period ( 1.5 for linear and $2.7 \%$ per day for exponential fitting method). The distribution of the healing rates $A$ and $\Theta$ for the parallel groups is shown in Fig. 4. The hypothesis that conventionally treated ulcers heal at the same healing rate as those treated with ES could be rejected at a significance level of $p=0.006$ in the case of the exponential method, but cannot be rejected with a chosen significance level of 0.05 in the case of the linear evaluation method ( $p=0.07)$.

Demonstration of the statistically significant difference between mean healing rates of control and ES-treated wounds with exponential and not linear evaluation methods demands an analysis of respective fitting errors. The results on accuracy of the exponential and linear model for our sample of 109 ulcers (Table II) showed that the hypothesis about equality of their fitting errors could be rejected with a significance level of 0.005 . For $48 \%$ of ulcers, the difference between the exponential and linear fitting error was less than or equal to $1 \%$. However, the mean fitting error values indicate that the exponential fitting method is preferable for our sample of 109 wounds.

The data stratified on the basis of the ulcer location is presented in Table III. The results and comparison are meaningful only for the locations for which the control and ES-treated groups had at least 10 ulcers each. These are sacral area, trochanters, and legs. It can be seen that, for the sacral area, the initial complexity of the ulcers in the control and EStreated group was similar. Mean healing rates, both linear and exponential, are significantly higher for the electrically
TABLE I

Initial Characteristics of Pressure Ulcers InCluded in the Control (CO) and ES-Treated Group. Abbreviations are as Follows: SD- Standard Deviation, SAC- Sacral area, TROCHTrochanter, GLUT- Gluteal Muscle, OT- Other Locations

\begin{tabular}{|c|c|c|}
\hline & CO group & ES-treated group \\
\hline Number of ulcers $(n)$ & 48 & 61 \\
\hline $\begin{array}{l}\text { Mean initial area } \\
\pm \mathrm{SD}\left(\mathrm{cm}^{2}\right)\end{array}$ & $17.2 \pm 20$ & $10.6 \pm 13.3$ \\
\hline $\begin{array}{l}\text { Mean initial depth } \\
\pm \mathrm{SD}(\mathrm{mm})\end{array}$ & & $3.0 \pm 8.5$ \\
\hline $\begin{array}{l}\text { Number of ulcers with initial depth } \\
<5 \mathrm{~mm}\end{array}$ & $36(75 \%)$ & $51(83 \%)$ \\
\hline Number of ulcers with granulation & $25(52 \%)$ & $27(44 \%)$ \\
\hline $\begin{array}{l}\text { Mean ulcer duration } \\
\pm \text { SD (days) }\end{array}$ & $\begin{array}{l}125 \pm 129 \\
(\mathrm{n}=41)\end{array}$ & $\begin{array}{l}158 \pm 284 \\
(\mathrm{n}=60)\end{array}$ \\
\hline $\begin{array}{l}\text { Number of ulcers on } \\
\text { sac. / troch. / legs / glut. / ot. }\end{array}$ & $20 / 11 / 10 / 4 / 3$ & $14 / 16 / 18 / 5 / 8$ \\
\hline
\end{tabular}
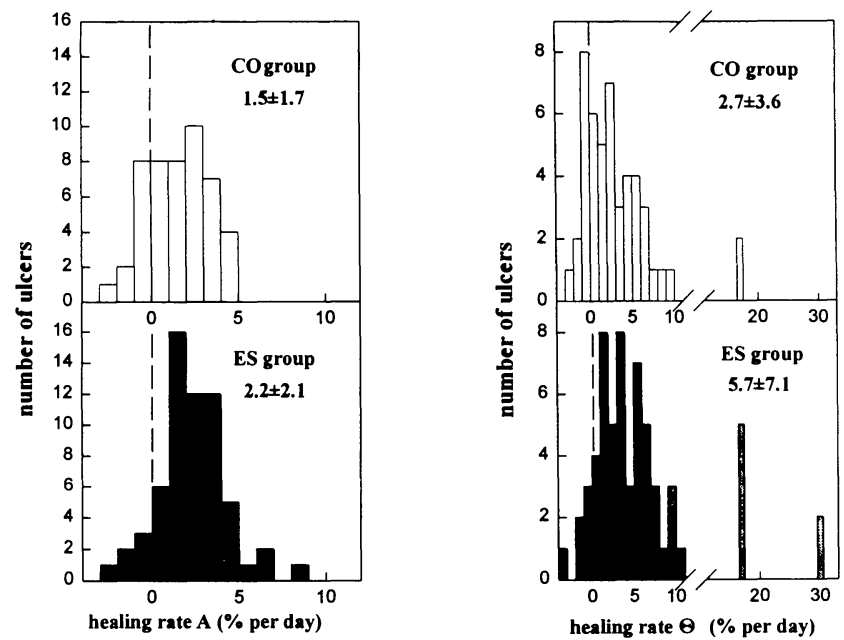

Fig. 4. The distribution of ulcer cases with regard to their healing rates for the control (CO) and ES-treated group. The mean healing rate values \pm standard deviation for each group are presented.

treated sacral pressure ulcers $(p<0.02)$. Ulcers located on the trochanters and included in the ES-treated group were, on the average, deeper than conventionally treated ulcers in the same location. However, mean values of the healing rates imply a shorter healing period for the ES-treated group. Similar results were obtained for the ulcers located on the legs. Table III shows that the initial complexity of the leg ulcers between the control and ES-treated groups is not similar. Control leg ulcers had larger initial areas, while ES-treated ulcers on the same location were initially deeper with less granulation.

An increase in ulcer depth was observed in five cases in the control and four cases in the ES-treated group. In two of these latter four ulcers, this cannot be regarded as a negative trend in healing as it was a consequence of debridement, i.e., removal of the remaining necrotic tissue and subsequent appearance 
TABLE II

EXPONENTIAL $\left(\varepsilon_{\text {exp }}\right)$ AND LiNEAR $\left(\varepsilon_{\text {lin }}\right)$ FITTING ERRORS FOR ULCERS INCLUDED IN THE STUDY

\begin{tabular}{|c|c|c|c|}
\hline & CO group & ES-treated group & All \\
\hline Number of ulcers $(n)$ & 48 & 61 & 109 \\
\hline Mean $\varepsilon_{c \phi p} \pm \mathrm{SD}(\%)$ & $3.7 \pm 6.0$ & $4.7 \pm 10.0$ & $4.3 \pm 8.5$ \\
\hline Mean $\varepsilon_{\operatorname{lin}} \pm \mathrm{SD}(\%)$ & $3.5 \pm 5.6$ & $9.7 \pm 14.0$ & $7.1 \pm 11.7$ \\
\hline $\begin{array}{l}\text { Number of ulcers } \\
\left|\varepsilon_{-}-\varepsilon_{\text {iin }}\right| \leq 1 \%\end{array}$ & $29(60 \%)$ & $23(38 \%)$ & $52(48 \%)$ \\
\hline $\begin{array}{l}\text { Number of ulcers } \\
\text { better exp. fit }\end{array}$ & $6(13 \%)$ & $27(44 \%)$ & $33(30 \%)$ \\
\hline $\begin{array}{l}\text { Number of ulcers } \\
\text { better lin. fit }\end{array}$ & $13(27 \%)$ & $11(18 \%)$ & $24(22 \%)$ \\
\hline
\end{tabular}

TABLE III

Data Presented in Table I Stratified on the Basis of Ulcer location. For the Superficial Ulcers, DePth $=1 \mathrm{Mm}$ Was Adopted. AbBreviations are as Follows: CO- Conventional TREatment, ES-TREATElectrical Stimulation with Pulsed CuRrent, SD- Standard Deviation, $\Theta$ - Exponential Healing Rate, A- Linear Healing Rate

\begin{tabular}{|c|c|c|c|c|c|c|}
\hline \multirow{2}{*}{$\begin{array}{l}\text { Ulcer location } \\
\text { Treatment }\end{array}$} & \multicolumn{2}{|c|}{ sacrum } & \multicolumn{2}{|c|}{ trochanters } & \multicolumn{2}{|c|}{ legs } \\
\hline & $\mathrm{CO}$ & ES-treat. & $\mathrm{CO}$ & ES-treat. & $\mathrm{CO}$ & ES-treat. \\
\hline Number of ulcers & 20 & 14 & 11 & 16 & 10 & 18 \\
\hline $\begin{array}{l}\text { Mean initial area } \\
\pm \text { SD }\left(\mathrm{cm}^{2}\right)\end{array}$ & $18.6 \pm 16.6$ & $16.2 \pm 17.4$ & $17.3 \pm 18$ & $18.3 \pm 15.3$ & $8.1 \pm 5.2$ & $4.5 \pm 3.0$ \\
\hline $\begin{array}{l}\text { Mean initial depth } \\
\pm \text { SD }(\mathrm{mm})\end{array}$ & $8.6 \pm 9.3$ & $7.1 \pm 9.5$ & $2.4 \pm 3.2$ & $6.7 \pm 13.8$ & $1.0 \pm 0.0$ & $3.1 \pm 4.2$ \\
\hline $\begin{array}{l}\text { Number of ulcers } \\
\text { initial depth }<5 \mathrm{~mm}\end{array}$ & $10(50 \%)$ & $7(50 \%)$ & $9(82 \%)$ & $11(68 \%)$ & $10(100 \%)$ & $13(72 \%)$ \\
\hline $\begin{array}{l}\text { Number of ulcers } \\
\text { with granulation }\end{array}$ & $10(50 \%)$ & $7(50 \%)$ & $5(45 \%)$ & $9(56 \%)$ & $7(70 \%)$ & $6(33 \%)$ \\
\hline $\begin{array}{l}\text { Mean } \Theta \pm \text { SD } \\
\text { (\% per day) }\end{array}$ & $1.8 \pm 2.8$ & $6.2 \pm 5.1$ & $3.4 \pm 4.2$ & $3.6 \pm 3.2$ & $3.2 \pm 2.3$ & $5.9 \pm 6.5$ \\
\hline $\begin{array}{l}\text { Mean } A \pm S D \\
\text { (\% per day) }\end{array}$ & $1.2 \pm 1.5$ & $2.6 \pm 1.8$ & $1.5 \pm 1.9$ & $1.8 \pm 1.5$ & $2.0 \pm 1.3$ & $2.2 \pm 1.5$ \\
\hline
\end{tabular}

of granulation tissue. A marked decrease (more than $5 \mathrm{~mm}$ ) of the ulcer depth was achieved in six out of 10 deep ulcers treated with ES, and in four out of 12 deep wounds in the control group.

\section{B. Crossover Group}

Out of 48 pressure ulcers in the control group, 20 crossed over into the ES-treated group (not included in the EStreated group analysis described above). Table IV contains data concerning the pressure ulcers included in the crossover group and their healing rates during the four weeks of conventional treatment and the same period of ES treatment. During the control period, when the ulcers were treated conventionally, the healing rates ranged between $-2.9 \%$ and $3.2 \%$ per day for the linear, and between $-2.2 \%$ and $6.2 \%$ per day for the exponential fitting method. After applying ES for four weeks, in all but one case $\left(B_{3}\right)$, an improvement in ulcer healing rate was observed. It ranged between $-0.3 \%$ and $5.4 \%$ per day for linear and between $-0.3 \%$ and $14.7 \%$ per day for the exponential fitting method. The examples of the timecourse of the ulcer area with the best fitted curve for cases $A, B_{1}, D, E_{1}, E_{2}, K$ are presented in Fig. 5. The statistical analysis (paired $t$-test) indicates that the hypothesis regarding the equality of the healing rates during the conventional and ES treatments could be rejected at a significance level of $p=$ 0.001 for both evaluation methods. A summary of obtained results, presenting the distribution of the healing rates for the crossover group, is shown in Fig. 6.

The positive trends in ulcer depth and/or appearance of granulation tissue were observed in four ulcers $\left(B_{3}, K, E_{3}, J_{3}\right)$ after four weeks of the control period and in nine ulcers ( $A, B_{1}, D, E_{1}, G, C_{2}, I, K, L$ ) after the same period of ES.

Ulcers in the patients involved in this study were observed for a maximum of one year. The final outcome of the treatment (complete ulcer closure) cannot be used as the quantification parameter because 20 patients from the control group crossed over to the ES-treated group after four weeks. However, closure as the main goal of all treatment modalities needs to be considered. Out of 81 pressure ulcers (61 from the ES-treated group and 20 from the crossover group) which received the ES treatment, 58 closed completely. Of these, 13 were deeper than $5 \mathrm{~mm}$, while 45 were superficial wounds. The average initial area of ulcers that healed after introduction of ES was $7.9 \pm 8.8 \mathrm{~cm}^{2}$. Out of 28 wounds treated with conventional therapy only, 15 pressure ulcers healed. All were superficial ulcers with an average initial area of $6.1 \pm 6.7 \mathrm{~cm}^{2}$.

\section{DISCUSSION}

The results presented demonstrate a very good therapeutic response of the pressure ulcers in SCI patients to treatment with pulsed electrical current.

Comparison of the control and ES-treated groups showed a higher average healing rate for ulcers treated with ES, indicating a 1.5 to 2 times shorter healing period. It is interesting to note that, in spite of there being 109 pressure ulcers included in the study, the size of the sample observed is still not large enough to exclude an imbalance in ulcer characteristics between groups introduced by the random assignment. Due to this nonhomogeneity of the groups, the comparison of control and ES-treated ulcers at particular anatomic locations might be more convincing (see Table III). However, we shall discuss more closely the results obtained in the crossover group, in which each wound served as its own control. In all but one ulcer out of 20 cases, an improvement in the healing rate was observed after the introduction of ES (see Table IV). In seven cases $\left(A, C_{1}, D, F, H, E_{2}, I\right)$ which showed resistance to healing or responded poorly to conventional therapy, we can attribute the considerable improvement in the healing process and complete ulcer closure to the introduction of ES (see also 


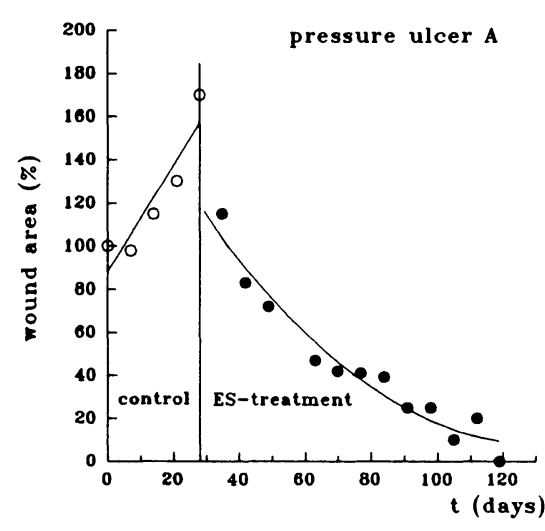

(a)

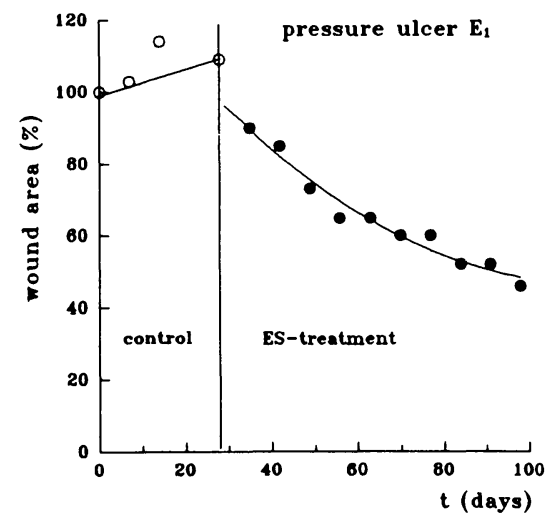

(d)

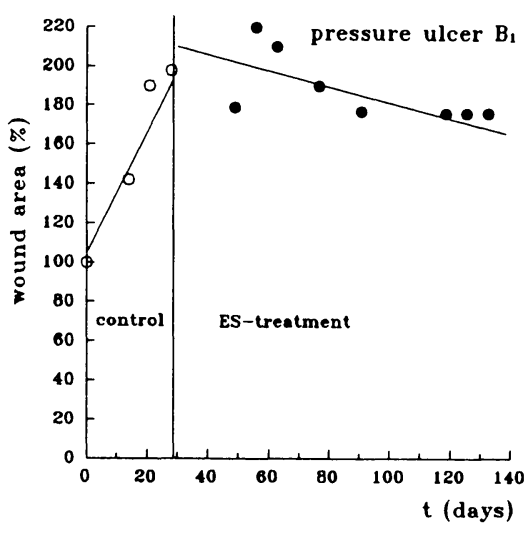

(b)

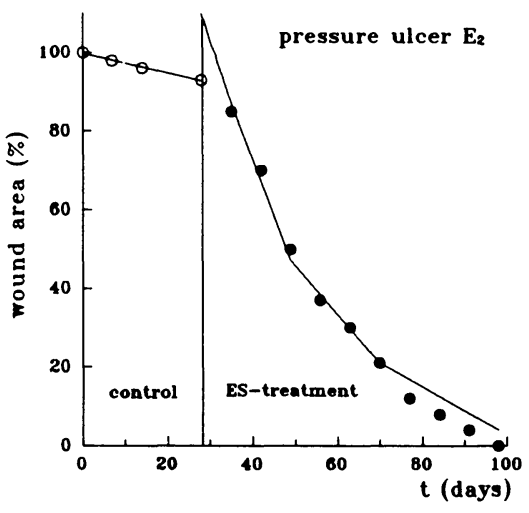

(e)

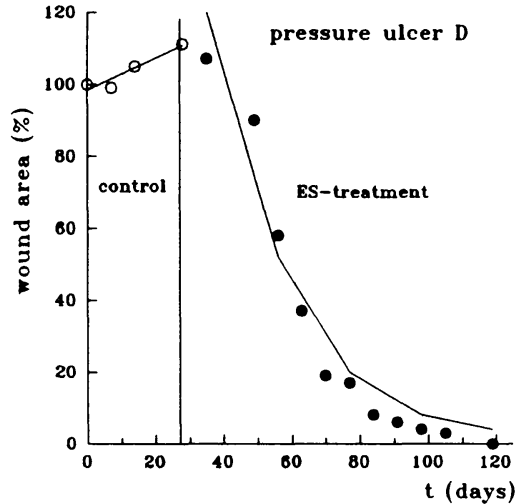

(c)

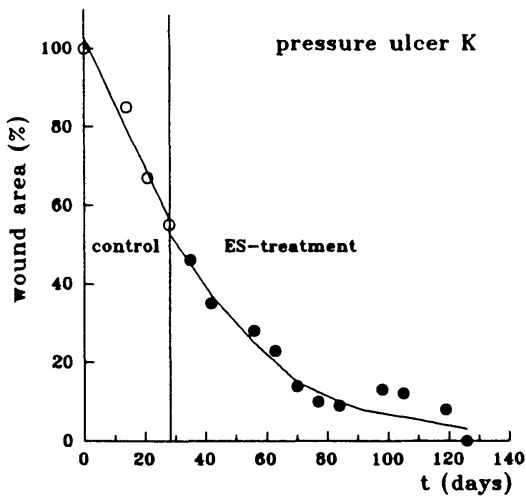

(f)

Fig. 5. Time-courses of the ulcer areas with the best fitted curve for wounds $A, B_{1}, D, E_{1}, E_{2}, K$.

examples in Fig. 5(a), (c), (e)). In seven cases which had already exhibited quite rapid healing when treated conventionally, further improved healing was obtained after applying ES treatment (see example in Fig. 5(f)). The successfulness of the healing of these wounds $\left(J_{1}, K, E_{3}, J_{2}, L, M, J_{3}\right)$ can not be attributed exclusively to ES, since the ulcer areas at the start of the application of ES were markedly smaller than the initial area values for the control period. In this case, much of the credit for complete closure can be attributed to conventional wound care. Three ulcers $\left(E_{1}, G, C_{2}\right)$ did not heal during the patients' stay at the Rehabilitation Institute, but the possibility of wound-closure was promising as the state of the wounds was improved, i.e., they decreased in depth and/or the granulation tissue appeared. In the remaining three ulcers $\left(B_{1}, B_{2}, B_{3}\right)$ belonging to the same patient, the healing process was not successfully affected by ES (see example in Fig. 5(b)). The pressure ulcer is affected by many variables within the human organism. Therefore, the dynamics of pressure ulcer healing depend on the patient's general health. This can be well illustrated in patients having more than one wound (see Table IV). Comparison of healing rates for the parallel groups and the crossover group reveal lower healing rates for the control period of the crossover group than for the control group. This is not surprising since patients in the control group who were unsatisfied with the extent of their healing during four weeks of conventional wound treatment crossed over to the ES treatment. Healing rates obtained in the crossover group
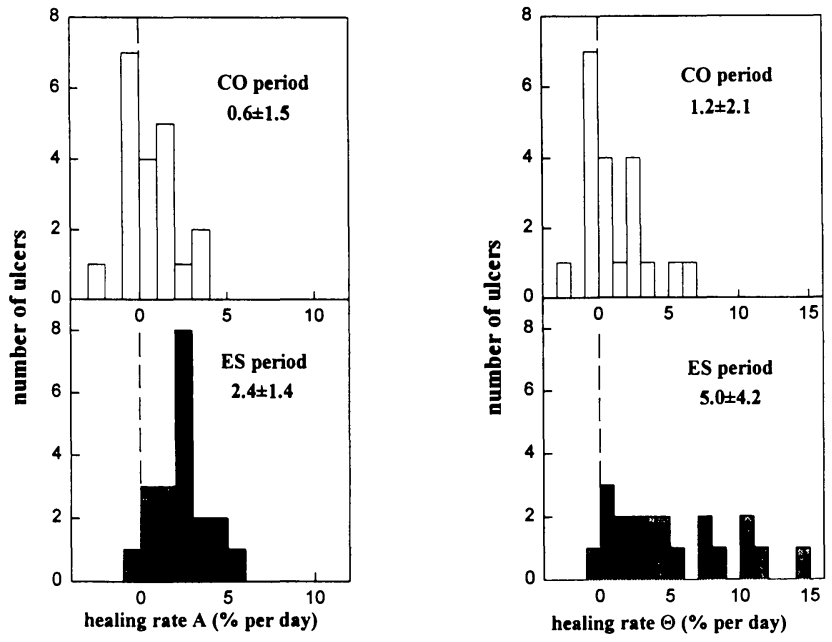

Fig. 6. The distribution of ulcer cases with regard to their healing rates for the crossover group. The mean healing rate values \pm standard deviations for each period are presented.

after four weeks of electrical stimulation are in agreement with the results obtained in the ES-treated group.

The results presented suggest that, in addition to conventional wound care, the simple and inexpensive ES treatment could initiate and/or accelerate pressure ulcer healing.

In searching for an explanation for the improved rate of healing caused by electrotherapy, several possible mechanisms have been proposed [9], [17], [19], [30]. Let us focus on the 
TABLE IV

Pressure Ulcers Included in the Crossover Group and Changes in Their area (Healing Rates-Linear and Exponential Fitting Method), Depth and Granulation appearance During the Conventional (CO Period), and Electrical Stimulation Treatment (ES Period). Ulcers Belonging to the Same Patient are Marked with the Same letter. For the Superficial Wounds, Depth $=1$ mM was adopted. Abbreviations are as Follows: LiN- Linear Healing Rate, EXP- Exponential Healing Rate, GLUTGluteal Muscle, SAC- Sacral Area, Troch- Trochanter, N- No, Y- Yes, M- Month, X- Data not Available, W- Week

\begin{tabular}{|c|c|c|c|c|c|c|c|c|c|}
\hline \multirow[t]{2}{*}{ Ulcer } & \multirow[t]{2}{*}{ Location } & \multirow[t]{2}{*}{$\begin{array}{c}\text { Initial area } \\
\left(\mathrm{cm}^{2}\right)\end{array}$} & \multirow[t]{2}{*}{$\begin{array}{c}\text { Initial depth (mm) / } \\
\text { granulation }(Y / N)\end{array}$} & \multirow[t]{2}{*}{ Duration } & \multicolumn{2}{|c|}{$\begin{array}{l}\text { Healing rate (\% per day) } \\
\text { lin. / exp. }\end{array}$} & \multicolumn{2}{|c|}{ Depth (mm) / granulation $(\mathrm{Y} / \mathrm{N})$} & \multirow{2}{*}{$\begin{array}{c}\text { Healed }(\mathrm{Y} / \mathrm{N}) \\
\text { Duration of } \mathrm{ES}\end{array}$} \\
\hline & & & & & CO period & ES period & $\mathrm{CO}$ period & ES period & \\
\hline $\mathbf{A}$ & glut. & 3.8 & $28 / \mathrm{N}$ & $4 \mathrm{M}$ & $-2.9 /-2.2$ & $2.2 / 4.1$ & $26 / N$ & $15 / Y$ & $\mathrm{Y} / 12 \mathrm{~W}$ \\
\hline $\mathrm{B}_{1}$ & troch. & 21.6 & $5 / N$ & $3 \mathrm{M}$ & $-1.4 /-1.0$ & $-0.3 /-0.3$ & $15 / \mathrm{N}$ & $20 / Y$ & $\mathrm{~N} / 8 \mathrm{~W}$ \\
\hline $\mathrm{C}_{1}$ & leg & 7.7 & $1 / Y$ & $4 \mathrm{M}$ & $-0.8 /-0.8$ & $3.5 / 7.5$ & $1 / Y$ & $1 / Y$ & $Y / 7 W$ \\
\hline $\mathbf{D}$ & glut. & 13.0 & $10 / N$ & $1 \mathrm{M}$ & $-0.4 /-0.4$ & $2.1 / 3.0$ & $39 / \mathrm{N}$ & $25 / Y$ & $\mathrm{Y} / 12 \mathrm{~W}$ \\
\hline $\mathbf{B}_{2}$ & sac. & 32.9 & $15 / Y$ & $3 \mathrm{M}$ & $-0.3 /-0.3$ & $0.4 / 0.4$ & $20 / Y$ & $20 / Y$ & $\mathrm{~N} / 8 \mathrm{~W}$ \\
\hline$E_{1}$ & sac. & 56.5 & $30 / \mathrm{N}$ & $\mathrm{X}$ & $-0.2 /-0.2$ & $1.5 / 1.9$ & $30 / \mathrm{N}$ & $20 / Y$ & $\mathrm{~N} / 10 \mathrm{~W}$ \\
\hline $\mathbf{F}$ & troch. & 2.2 & $1 / Y$ & $20 \mathrm{M}$ & $0.0 / 0.0$ & $2.4 / 3.6$ & $1 / Y$ & $0 / \mathrm{Y}$ & $\mathrm{Y} / 3 \mathrm{~W}$ \\
\hline G & troch. & 45.9 & $1 / \mathrm{N}$ & $\bar{X}$ & $0.0 / 0.0$ & $0.8 / 0.9$ & $1 / \mathrm{N}$ & $1 / Y$ & $\mathrm{~N} / 12 \mathrm{~W}$ \\
\hline $\mathrm{H}$ & troch. & 2.0 & $1 / Y$ & $2 M$ & $0.2 / 0.2$ & $2.9 / 5.1$ & $1 / Y$ & $1 / Y$ & $\mathrm{Y} / 6 \mathrm{~W}$ \\
\hline$E_{2}$ & shin & 62.8 & $1 / \mathrm{Y}$ & $\mathrm{x}$ & $0.2 / 0.2$ & $2.3 / 3.2$ & $1 / \mathrm{Y}$ & $1 / Y$ & $\mathrm{Y} / 10 \mathrm{~W}$ \\
\hline$C_{2}$ & sac. & 35.5 & $16 / Y$ & $4 \mathrm{M}$ & $0.5 / 0.6$ & $1.4 / 1.8$ & $16 / Y$ & $1 / Y$ & $\mathrm{~N} / 12 \mathrm{~W}$ \\
\hline $\mathrm{B}_{3}$ & leg & 8.3 & $3 / Y$ & $3 \mathrm{M}$ & $0.6 / 0.7$ & $0.2 / 0.2$ & $1 / \mathrm{Y}$ & $1 / Y$ & $\mathrm{~N} / 8 \mathrm{~W}$ \\
\hline I & sac. & 21.9 & $5 / N$ & $2 M$ & $1.3 / 1.8$ & $2.9 / 8.3$ & $6 / N$ & $1 / \mathrm{Y}$ & $\mathrm{Y} / 5 \mathrm{~W}$ \\
\hline$J_{1}$ & leg & 4.8 & $1 / Y$ & $4 \mathrm{M}$ & $1.5 / 2.0$ & $5.4 / 14.7$ & $1 / \mathrm{Y}$ & $1 / Y$ & $\mathrm{Y} / 5 \mathrm{~W}$ \\
\hline $\mathbf{K}$ & sac. & 15.7 & $30 / \mathrm{N}$ & $1 \mathrm{M}$ & $1.6 / 2.1$ & $1.7 / 2.3$ & $22 / Y$ & $10 / Y$ & $\mathrm{Y} / 12 \mathrm{~W}$ \\
\hline$E_{3}$ & shin & 94.3 & $3 / Y$ & $\mathbf{x}$ & $1.8 / 2.6$ & $2.6 / 4.0$ & $1 / Y$ & $1 / Y$ & $\mathrm{Y} / 10 \mathrm{~W}$ \\
\hline$J_{2}$ & leg & 20.4 & $1 / Y$ & $4 M$ & $2.1 / 2.9$ & $3.9 / 10.3$ & $1 / Y$ & $0 / \mathrm{Y}$ & $\mathrm{Y} / 4 \mathrm{~W}$ \\
\hline $\mathbf{L}$ & sac. & 23.5 & $16 / N$ & $3 \mathrm{M}$ & $1.8 / 3.4$ & $2.6 / 11.8$ & $15 / N$ & $12 / Y$ & $\mathrm{Y} / 12 \mathrm{~W}$ \\
\hline $\mathbf{M}$ & sac. & 31.4 & $1 / Y$ & $5 \mathrm{M}$ & $3.2 / 5.5$ & $4.1 / 10.0$ & $1 / \mathrm{Y}$ & $0 / Y$ & $\mathrm{Y} / 4 \mathrm{~W}$ \\
\hline$J_{3}$ & leg & 8.6 & $3 / Y$ & $4 M$ & $3.1 / 6.2$ & $4.4 / 7.9$ & $1 / \mathrm{Y}$ & $0 / \mathrm{Y}$ & $\mathrm{Y} / 4 \mathrm{~W}$ \\
\hline
\end{tabular}

physiological effects of the ES used in this study. Electrical stimulation of skeletal muscle has been shown to be capable of increasing muscle blood flow with the most effective frequency range being between 16 and 50 pps [31], [32]. Tracy et al. have reported that a significant increase in blood flow to a muscle could be achieved using stimulation parameters similar to those we used (biphasic pulses, stimulation trains 4 $\mathrm{s}$ on $/ 4 \mathrm{~s}$ off, a frequency range of 10 to $50 \mathrm{pps}$, stimulation intensity sufficient to produce torque equal to $15 \%$ of the predetermined maximal voluntary muscle contraction). The greatest effect was observed at $50 \mathrm{pps}$ [31]. In our study, the frequency of 40 pps combined with the current amplitude adjusted to achieve minimal muscle contraction may have facilitated healing through improved blood flow [33].

The rhythmical exchanges of stimulation trains and pauses, as used in our study, perform a massage effect not only on the skeletal muscles in the ulcer area but also on the smooth muscles within the walls of blood vessels. Following smooth muscle contraction and relaxation increased blood flow likely occured [34]. In our study, this relaxation could occur every $8 \mathrm{~s}$ during the $2 \mathrm{~h}$ of ES treatment.

Blood vessels supplying skeletal muscles possess a considerable vasodilator sympathetic nervous supply, which could also be activated by ES.
Chemical vasodilatation associated with increased metabolic activity is another mechanism that may enhance tissue healing [35], [36]. Minimal muscle contraction elicited by electrical stimulation in the vicinity of the ulcer may induce increased metabolic demands, thus initiating chemical processes resulting in improved blood flow.

All the listed mechanisms serve the same purpose, which is to improve the energy supply of the stimulated tissue through improved blood flow. The enhancement of blood flow by ES in the ulcer region could be a trigger and/or accelerator for the healing process by providing better conditions for the essential functions of some cells, such as the reparative capacity of macrophages, fibroblasts, keratinocytes, and endothelial cells [4], [37], [38].

An additional observation we made, and one which has been noted by others [18], concerns the improved quality of the newly developed tissues after the application of ES, a process which needs to be verified and objectified. The longterm benefits derived from the stronger and more elastic and aesthetic scar resulting from ES treatment could be of great interest for plastic surgery and skin/muscle flap surgery.

Insufficient blood supply and damaged microcirculation from pressure induced ischemia are often stated as the primary cause of pressure ulcer formation and the advantages of 
employing ES for prevention of pressure ulcers have already been implemented [39]. But in preventive management, it is even more difficult to provide persuasive evidence of the efficacy of ES.

The further optimization of stimulation parameters and extensive studies on mechanisms by which ES augments wound repair could provide clinically applicable information about chronic wound healing and conditions for which ES treatment may be most effective.

\section{REFERENCES}

[1] R. Harries, "Personal experience of pressure sores," Physiotherapy, vol. 73, pp. 448-50, 1987.

[2] J. S. Young, "Pressure sores," in Spinal Cord Injury Statistics, J. S. Young, P. E. Burns, A. M. Bowen, and R. McCutchen, Eds. Phoenix: Good Samaritian Med. Cen., 1982, pp. 95-122.

[3] L. Guttmann, "Pressure sores," in Handbook of Clinical Neurology; Injuries of the Spine and Spinal Cord, P. J. Vinken, G. W. Bruyn, and R. Braakman, Eds. New York: American Elsevier and North Holland Publ. Co., 1960, pp. 463-476.

[4] T. A. Krouskop, P. C. Noble, S. L. Garber, and W. A. Spencer, "The effectiveness of preventive management in reducing the occurrence of pressure sores," J. Rehab. $R \& D$, vol. 20, pp. 73-83, 1983.

[5] R. M. Allman, "Pressure ulcers among the elderly," N. Eng. J. Med., vol. 320, pp. 850-853, 1989.

[6] D. Assimacopoulos, "Wound healing promotion by the use of negative electric current," Am. Surg., vol. 34, pp. 423-431, 1968.

[7] L. C. Carey and D. Lepley, "Effect of continuous direct electric current on healing wounds," Surg. Forum, vol. 13, pp. 33-35, 1962.

[8] W. R. Gault and P. F. Gatens, "Use of low intensity direct current in management of ischemic skin ulcers," Phys. Ther., vol. 56, pp. 265-269, 1976.

[9] P. C. Wheeler, L. E. Wolcott, J. L. Morris, and M. R. Spangler, "Neural consideration in the healing of ulcerated tissue by clinical electrotherapeutic application of weak direct current: Findings and theory," in Neuroelectric Research. D. V. Reynolds and A. E. Sjoberg, Eds. Springfield: Charles Thomas Publ., 1971, pp. 83-99.

[10] P. J. Carley and S. F. Wainapel, "Electrotherapy for acceleration of wound healing: Low intensity direct current," Arch. Phys. Med. Rehab., vol. 66, pp. 443-446, 1985 .

[11] J. M. Wood, W. E. Jacobson, K. U. Schallreuter, P. Evans, III, M Jacobson, R. Suffer, J. Newman, and C. White, "Pulsed low-intensity direct current (PLIDC) is effective in healing chronic decubitus ulcers in stages II and III," J. Invest. Dermatol., vol. 98, no. 4, p. 574, 1992.

[12] J. A. Feedar, L. C. Kloth, and G. D. Gentzkow, "Chronic dermal ulcer healing enhanced with monophasic pulsed electrical stimulation," Phys. Ther., vol. 71, pp. 639-649, 1991.

[13] J. W. Griffin, R. E. Tooms, R. A. Mendius, J. K. Clifft, R. Vander Zwaag, and F. El-Zeky, "Efficacy of high voltage pulsed current for healing of pressure ulcers in patients with spinal cord injury," Phys. Ther., vol. 71, pp. 433-444, 1991.

[14] L. C. Kloth and J. A. Feedar, "Acceleration of wound healing with high voltage, monophasic, pulsed current," Phys. Ther., vol. 68, pp. $503-508,1988$

[15] T. Lundeberg, J. Kjartansson, and U. Samuelsson, "Effect of electrical nerve stimulation on healing of ischaemic skin flaps," The Lancet, pp. 712-714, Sept. 24, 1988

[16] R. Karba, L. Vodovnik, M. Prešern-Štrukelj, and M. Klešnik, "Promoted healing of chronic wounds due to electrical stimulation," Wounds, vol. 3, pp. 16-23, 1991.

[17] B. Kaada and M. Emru, "Promoted healing of leprous ulcers by transcutaneous nerve stimulation," Acupuncture Electro., vol. 13, pp. $165-176,1988$.

[18] J. H. Goldin, N. R. G. Broadbent, J. D. Nancarrow, and T. Marshall, "The effects of Diapulse on the healing of wounds: A double-blind randomised controlled trial in man," Br. J. Plast. Surg., vol. 34, pp. 267-270, 1981

[19] M. Ieran, S. Zaffuto, G. Bagnacani, M. Annovi, A. Moratti, and R. Cadossi, "Effects of low frequency pulsing electromagnetic fields on skin ulcers of venous origin in humans: A double-blind study," $J$. Orthop. Res., vol. 8, pp. 277-282, 1990.

[20] A. M. Rosenthal and A. Schurman, "Hyperbaric treatment of pressure sores," Arch. Phys. Med. Rehab., vol. 52, pp. 413-415, 1971.
[21] M. Dyson and J. Suckling, "Stimulation of tissue repair by ultrasound: A survey of the mechanisms involved," Physiotherapy, vol. 64, no. 4, pp. 105-108, 1978.

[22] G. R. Grotendorst, "Growth factors as regulators of wound repair," Int. J. Tissue Reac., vol. 10, pp. 337-344, 1988.

[23] G. L. Brown, L. B. Nanney, J. Griffen, A. B. Cramer, J. M. Yancey, L. J. Curtsinger, L. Holtzin, G. S. Schultz, M. J. Jurkiewicz, and J. B. Lynch, "Enhancement of wound healing by topical treatment with epidermal growth factor," N. Eng. J. Med., vol. 231, pp. 76-79, 1989.

[24] L. Vodovnik and R. Karba, "Treatment of chronic wounds by means of electric and electromagnetic fields: Part 1-Literature review," Med. \& Biol. Eng. \& Comp., vol. 30, pp. 257-266, 1992.

[25] L. Vodovnik, M. R. Dimitrijevic, T. Prevec, and M. Logar, "Electronic walking aids for patients with peroneal palsy," Wld. Electron Instr., vol 4, pp. 58-61, 1966.

[26] L. Vodovnik, S. Rebersek, A. Stefanovska, and T. Bajd, "Indirect and direct effects of electrical currents on pathological neuromuscular systems," Studia. Biophysica, vol. 112, pp. 99-104, 1986.

[27] J. A. Feedar and L. C. Kloth, "Conservative management of chronic wounds," in Wound Healing: Alternatives in Management, L. C. Kloth, J. M. McCulloch, and J. A. Feedar, Eds. Philadelphia: F. A. Davis Co., 1990, pp. 135-172.

[28] A. Stefanovska, L. Vodovnik, H. Benko, M. Malezic, R. Turk, A. Kolenc, and S. Rebersek, "Enhancement of ulcerated tissue healing by electrical stimulation," in Proc. RESNA IOth Annu. Conf., San Jose, pp. 585-587, 1987.

[29] N. Rashevsky, Mathematical Biophisic. New York: Dover Publ., 1960, pp. 299-306.

[30] L. C. Kloth and J. A. Feedar, "Electrical stimulation in tissue repair," in Wound Healing: Alternatives in Management, L. C. Kloth, J. M McCulloch, and J. A. Feedar, Eds. Philadelphia: F. A. Davis Co., 1990, pp. 221-257.

[31] J. E. Tracy, D. P. Currier, and A. J. Threlkeld, "Comparison of selected pulse frequencies from two different electrical stimulators on blood flow in healthy subjects," Phys. Ther., vol. 68, pp. 1526-1532, 1988.

[32] T. M. Mohr, "Effect of electrical stimulation on blood flow response," Phys. and Rehab. Med. CRC, vol. 1, pp. 211-229, 1990.

[33] B. Likar, S. Rencel, M. Presern-Strukelj, and M. Kleznik, "Analysis of changes of thermal conditions in wounds due to electrical stimulation," Trans. BRAGS, Cleveland, USA, vol. 9, p. 45, 1989.

[34] T. W. Rooke, T. J. Rimele, and P. M. Vanhoutte, "Relaxation of canine saphenous vein following brief transmural nerve stimulation," Am. J. Physiol.: Heart Circ. Physiol., vol. 14, pp. H1073-H1076, 1983.

[35] J. C. Longhurst and J. H. Mitchell, "Reflex control of the circulation by afferents from skeletal muscle," in Cardiovascular Physiology III, Internal Review Physiology, A. C. Guyton and D. M. Yound, Eds. Maryland: University Park Press, 1979, pp. 125-148.

[36] E. Assmussen, M. Nielsen, and G. Wieth-Pedersen, "On the regulation of circulation during muscular work," Acta. Physiol. Scand., vol. 6, pp. 253-257, 1943

[37] J. D. Whitney, "Physiologic effects of tissue oxygenation on wound healing," Heart Lung, vol. 18, pp. 466-474, 1989.

[38] T. K. Hunt, "The physiology of wound healing," Ann. Emerg. Med., vol. 17 , pp. 1265-1273, 1988.

[39] S. P. Levine, R. L. Kett, P. S. Cederna, and S. V. Brooks, "Electric muscle stimulation for pressure sore prevention: Tissue shape variation," Arch. Phys. Med. Rehab., vol. 71, pp. 210-215, 1990.

Aleksandra Jerčinović graduated in 1989 and received the M.Sc. degree in electrical engineering in 1992 from the Faculty of Electrical and Computer Engineering, University of Ljubljana, Slovenia.

From 1989 to 1991, she was a Research Associate at the Laboratory of Biocybernetics at the same university where her work was mainly devoted to the effects of externally applied electrical currents on wound healing and measurements of endogenous electrical potentials of skin injuries. Since 1992 she has been working at the Department of Orthopaedics-Traumatology, at the University Hospital Erasme in Brussels, where she continues to work in the same research field. Her main interests are the effects of electromagnetic fields on biological systems, measurements of electrical properties of biological tissues and mathematical modeling of the electromagnetic field distribution in biological systems. 
Renata Karba (S'94) received B.S. and M.Sc. degrees in electrical engineering from the Faculty of Electrical and Computer Engineering, University of Ljubljana, Slovenia. Currently, she is working towards the Ph.D. degree in electrical engineering, dealing with basic mechanisms of therapeutic effects of electrical stimulation and optimization of stimulation parameters for chronic wound healing enhancement.

From 1987 to 1993, she was a Research Associate at the Laboratory of Biocybernetics at the Faculty of Electrical and Computer Engineering in Ljubljana, where she studied responses of skeletal muscles to electrical stimulation, as well as therapeutic effects of electric currents on healing soft and bone tissue.

Lojze Vodovnik (SM'73-F'92) completed his studies at the Faculty of Electrical Engineering, University of Ljubljana, Slovenia.

He was a Research Associate and Visiting Professor from 1964 to 1969 at Case Western Reserve University, Cleveland, $\mathrm{OH}$, and World Rehabilitation Fund Fellow in 1981 at Rancho Los Amigos Hospital, Los Angeles, CA. Currently, he is a Professor of Biocybernetics and Neurocybernetics at the Faculty of Electrical Engineering, University of Ljubljana, Slovenia.

Dr. Vodovnik is a member of the Slovenian Academy of Science and Arts, a Senior Member of the Biomedical Engineering Society, and a Member of the Board of Directors of the European Society for Engineering and Medicine, as well as of the European Bioelectromagnetics Association.

Aneta Stefanovska (M'90) was born in Kriva Palanka, Macedonia, former Yugoslavia. She studied at the Faculty of Electrical and Computer Engineering, University of Ljubljana, where she received the M.Sc. degree in 1988 and the Ph.D. degree in 1992 (on self-organization of biological systems influenced by electric currents). Part of her Ph.D. research work was performed at the Institute for Theoretical Physics and Synergetics, University of Stuttgart, Germany.

She is currently an Assistant Lecturer in Digital Electronics, Biocybernetics and Neurocybernetics at the Faculty of Electrical and Computer Engineering, University of Ljubljana, Slovenia. Her research interest is in dynamics of biological systems.

Peter Krošelj received the B.S. and M.Sc. degrees in electrical engineering from the Faculty of Electrical and Computer Engineering, University of Ljubljana, Slovenia.

His main research interests include biomedical signal processing and software engineering.
Rajko Turk was born in 1933 in Ljubljana, where he graduated from the Faculty of Medicine, University of Ljubljana in 1958. He completed his specialization in physical medicine and rehabilitation in Ljubljana in 1967. Thereafter, he attended a one-year course in rehabilitation, organized by WHO at the University of Copenhagen and partially in Sweden, Great Britain, and Ireland.

From 1972 to 1993, he was Head of the Department of Spinal Cord Injury at the University Rehabilitation Institute, Ljubljana.

Ivan Džidić was born in Ljepunice in Bosnia and Herzegovina. He graduated from the Medical Faculty, University of Zagreb in 1975. In 1982, he completed his specialization in physical medicine and rehabilitation and received the Ph.D. degree in 1987 from the same university.

Currently, he is Head of the SCI Department at the Hospital for Rehabilitation in Varazdinske Toplice, Croatia.

Helena Benko is a Senior Physical Therapist at the Department of Spinal Cord Injury, University Rehabilitation Institute, Ljubljana, Slovenia. Besides the routine work, she has been involved in research into the effects of electrical currents in the restoration of movement in hemiplegic and spinal cord injured subjects and their possible therapeutic effects since 1970. She was a member of the team which, in 1981, proposed the four-channel pattern of paraplegic gait with electrical stimulation. She has been involved in numerous stimulation education programs and is also an Instructor for rehabilitation of SCI patients at the University of Ljubljana.

Rajmond Šavrin was born in 1955 in Ljubljana. In 1981, he graduated from the Faculty of Medicine at the University of Ljubljana, Slovenia. In 1988, he completed his specialization in physical medicine and rehabilitation.

$\mathrm{He}$ has been involved in the rehabilitation of patients with spinal cord injuries since 1982. In 1988, he became an Assistant at the SCI Department. Since 1991, he has been Head of the SCI Department at the Rehabilitation Institute in Ljubljana, Slovenia.

Dr. Šavrin is a regular member of the International Medical Society of Paraplegia. 